\title{
A representação como herança: uma análise biográfica dos eleitos para as Assembleias Legislativas no Brasil em $2018^{1}$
}

\author{
Philippe Chaves Guedon ${ }^{2}$ \\ Recebido em maio de 2019 \\ Aceito em outubro de 2019
}

\section{RESUMO}

A agenda de estudos sobre democracia no Brasil esteve centrada até o começo do presente século em temas como a retirada do entulho autoritário e a construção e discussão institucional que, nesse momento, nortearia o novo momento de abertura política. Após esse momento, abriu-se espaço não mais para discutir tão somente sobre a recém (re)inaugurada democracia, mas, além disso, pôde concentrar em temas relacionados a qualidade democrática. Uma das linhas oriundas desse grande tema é, por certo, a análise da representação política. Diante disso, o presente artigo analisa a composição das Assembleias Legislativas eleitas em 2018 a fim de verificar em que medida há a reprodução da representação política dentro das famílias que detém ou detiveram poder em seus respectivos estados. As singularidades da proposta são quantificar o fenômeno a partir da análise biográfica dos eleitos em todos os Estados da federação a fim de verificar as Assembleias com maior incidência de "presença genealógica' e, além disso, incluir a variável gênero, que possibilita discutir a maior incidência de "capital político herdado" nas representantes do sexo feminino.

Palavras-chaves: Genealogia; Representação política; Perfil parlamentar; Capital político; Capital político herdado.

\section{Representation as inheritance: a biographical analysis of the elected to the Legislative Assemblies in Brazil in 2018}

\begin{abstract}
The agenda of studies agenda on democracy in Brazil was focused until the beginning of the present century on topics such as the removal of authoritarian remains and the construction and institutional discussion that, at that time, would guide the new moment of political openness. After this moment, space was opened to no longer only discuss the newly (re)inaugurated democracy, but, in addition, to focus on issues related to democratic quality. One of the lines arising from this great theme is, of course, the analysis of political representation. Hence, this article analyzes the composition of legislative assemblies elected in 2018 in order to verify to what extent there is the reproduction of political representation within the families that hold or have held power in their respective states. The singularities of the current proposal are to quantify the phenomenon from the biographical analysis of elected officials in all states of the federation in order to verify the Assemblies with the highest
\end{abstract}

$1 \mathrm{O}$ presente trabalho foi apresentado como comunicação oral no X Seminário Nacional de Sociologias \& Política da UFPR no GT 3 - Instituições e poder: parentescos e genealogias. O autor agradece pelos comentários dos participantes da mesa que colaboraram para o aprimoramento do artigo.

2 Doutorando em História, Política e Bens Culturais do CPDOC/FGV. Bolsista CAPES. E-mail: philippe_guedon@hotmail.com 
incidence of 'genealogical presence' and, moreover, include the gender variable, which makes possible to discuss the higher incidence of "inherited political capital" in female representatives.

Keywords: Genealogy; Political representation; Parliamentary profile; Political capital; Inherited political capital.

\section{Introdução}

Na Ciência Política brasileira muito se discute sobre a qualidade da democracia. Desde os anos 90 pode-se afirmar que há uma agenda que analisa o desenho institucional cunhado ante a redemocratização e a operação cotidiana do universo da política em temas centrais como a governabilidade e as eleições. Via de regra, são abordagens influenciadas pela perspectiva neoinstitucionalista, centrada sobretudo na interação do arcabouço institucional e aqueles que operam nesses contextos, especialmente os partidos políticos.

Diante disso, outras variáveis também importantes para o sucesso eleitoral são, de certa forma, tratadas de forma menos importante. Neste artigo, argumentamos, assim como Oliveira (2012), que a variável “família” importa. A hipótese central do artigo é que parte considerável dos indivíduos eleitos possuem histórico familiar de atuação no universo da política institucional de forma a terem acesso desigual a recursos caros a competição eleitoral. Testa-se a hipótese no total de eleitos a Deputado Estadual em 2018 em todas as 26 Assembleias Legislativas e a Câmara Legislativa do Distrito Federal. Além disso, busca qualificar a transmissão desse "capital político" também a partir da perspectiva de gênero de modo verificar se há diferenças nessa transmissão.

Metodologicamente, o artigo conta com instrumental quantitativo construído a partir de três fontes diversas: o Dicionário Histórico Biográfico Brasileiro do CPDOC/ FGV; os perfis oficiais dos eleitos nos sites das Assembleias Legislativas e da Câmara Legislativa do Distrito Federal; e as páginas oficiais dos candidatos nas redes sociais e seus websites. ${ }^{3}$ Ao final do processo de coleta, o banco de dados contou com os 1059

3 Todos os eleitos também tiveram seus nomes pesquisados em ferramentas de busca online e em clipagens de notícias de modo a complementar informações que eventualmente não estivessem disponíveis nas páginas oficiais. 
deputados eleitos com o respectivo partido, a sinalização da existência ou não do que chamamos de "capital político herdado" 4 , a origem desse capital, a relação familiar e o cargo ocupado pelo indivíduo 5 .

Além desta breve introdução, o artigo é construído a partir da discussão teórica que embasa a análise empírica e a apresentação dos dados quantitativos coletados. Por fim, são apresentadas as considerações finais sobre a relação entre família, eleição e democracia.

\section{Política, poder e família: aproximações teóricas e empíricas}

Já assunto corriqueiro nas mídias, fato é que a democracia brasileira é permeada, em muito, pelo poder de grupos familiares. Não raras são as reportagens e os estudos jornalísticos que entrelaçam a família e o sucesso eleitoral. ${ }^{6}$ Contudo, nas discussões da área de ciências humanas a categoria "família" não obtém o mesmo prestígio.

Nas obras clássicas de teoria social brasileira é possível afirmar que a categoria "família" explicava em boa parte a conformação estrutural e relacional da sociedade brasileira. São exemplos dessas interpretações Oliveira Viana (1920), Gilberto Freyre (1933) e Sérgio Buarque de Holanda (1936). Via de regra, são interpretações que apresentam o Brasil rural diante das suas relações patriarcais e que consolidam uma gramática única para representar a política brasileira: clientelista, envoltada nas relações de coronelismo e mandonismo (CARVALHO, 1997).

Ao mesmo passo há o Brasil passa por um período de industrialização e urbanização, as áreas de conhecimento das humanidades iniciam também seu processo de consolidação. O "abandono" da temática familiar é, de certo modo, um reflexo desse processo. Isso é melhor ilustrado no cenário do desenvolvimento da

4 O conceito está descrito na discussão dos resultados.

5 Em indivíduos que ocuparam mais de um cargo optou-se por considerar o mais alto na sua trajetória a partir de uma noção de carreira política ascendente: Vereador; Prefeito (cidade pequena); Prefeito (cidade média); Deputado Estadual; Deputado Federal; Prefeito (capital/grande cidade); Senador; Governador; Presidente da República (Miguel, 2003).

6 Exemplo de reportagens: https://theintercept.com/2018/09/o2/familias-tradicionaisdominam-a-politica-brasileira-e-isso-nao-tem-hora-pra-acabar/ (Acesso em 21/04/2019); https://wwwı.folha.uol.com.br/poder/2018/o8/dinastias-politicas-do-brasil-lancam-mais-de-6ocandidatos-nas-eleicoes.shtml (Acesso em 21/04/2019). 
Ciência Política brasileira. Lynch (2016) afirma que nos anos 6o e 70 houve uma certa autonomização do campo, sobretudo com o apoio dos EUA e da Fundação Ford para construir uma Ciência Política empiricamente orientada.

Diante dessa matriz, o Brasil passou a assumir uma noção "politológica" do objeto estudado, segundo Leite (2015). Essa abordagem privilegiaria a noção da política orientada pela institucionalidade e pelo Estado. No mesmo sentido, Canêdo (2005) afirma que a área de humanidades importou epistemologias para compreender o Brasil, sendo Duverger (1951) um dos influenciadores na mudança de orientação do objeto "família” para o objeto "partido político".

Diante disso, a temática familiar foi tratada como menor ou desviante dentro dos novos modelos que buscavam explicar a institucionalidade brasileira. Para além disso, os esforços realizados de entender a relação entre família e política foram encarados como fenômeno típico do localismo (OLIVEIRA, GOULART, VANALI e MONTEIRO, 2017). Em outras palavras, na tentativa de afirmar a política como um campo autônomo, os traços de manutenção da ordem arcaica eram pouco interessantes para a argumentação.

Oliveira et al (2017) afirmam que somente nos anos 90 retomou-se a discussão sobre a relação entre esses dois conceitos. Isso porque, mesmo diante de todas as transformações ocorridas na sociedade brasileira, não foi possível limitar a presença de relações familiares no campo político. Além disso, esses grupos familiares adaptaramse ao novo ambiente construindo estratégias de manutenção de poder (p.172).

O argumento central é, portanto, que a redemocratização e os desenhos institucionais criados não foram capazes de superar traços do Brasil "arcaico" como a justaposição entre o público e o privado. Diante disso, emergiu necessidade de construir novo corpus teórico-metodológico para tratar desse fenômeno.

O caminho encontrado pelos pesquisadores do campo foi de combinar as abordagens de cunho histórico-biográfico com as análises institucionalistas. Assim, as relações familiares importam tanto quanto a institucionalidade. Um dos exemplos desse pensamento está expresso em Oliveira (2012): 
"Minha tese é simples. Família ainda importa. As estruturas de parentesco formam parte da realidade social e política brasileira no século XXI. Redes familiares controlam partidos políticos, controlam o centro do poder executivo e formam redes atravessando o poder legislativo com parlamentares hereditários, sempre se renovando pelas gerações" (OLIVEIRA, 2012, p.13).

Canêdo (2011) trabalha com a ideia de que a presença de familiares na política seriam a expressão de um capital simbólico passível de transmissão. Sendo assim, considerando as eleições como uma disputa desigual de recursos, os detentores desse capital político seriam privilegiados.

Já há extensa literatura sobre os perfis privilegiados nas disputas eleitorais. Os dados empíricos demonstram que indivíduos homens, brancos, com maiores recursos financeiros em campanhas eleitorais, maior tempo de televisão e maiores níveis de escolaridade são mais propensos ao êxito eleitoral (COSTA, CODATO e PERISSINOTTO, 2015; CAMPOS, 2015; BORBA e CERVI, 2017). Esses estudos compuseram a agenda de pesquisa sobre recrutamento e analisaram, principalmente, a diferença entre os perfis dos candidatos a cargos eletivos e dos eleitos. É, segundo Perissinotto (2009), a agenda de estudo sobre “os que chegaram lá”, demonstrando já que eram indivíduos dotados de elementos mais eletistas do que os que haviam ficado pelos degraus do recrutamento partidário (NORRIS, 1997).

Em complemento a essa arena de estudos, argumentamos que as famílias são ativos fundamentais nos pleitos. São também elementos transmissíveis e definidores do êxito eleitoral. Os dados a seguir buscam entender essa relação.

\section{O caso das Assembleias Legislativas em 2018}

Oliveira et al (2017) afirma que "indivíduos pertencentes às tradicionais e endinheiradas famílias têm ocupado, de forma hegemônica e contínua, cargos eletivos e funções de nomeação das esferas municipais, estaduais e federais” (p.167). Um dado que corrobora essa constatação é que 2/3 dos Deputados Federais e 3/4 dos Senadores pertencem a famílias políticas (SARDINHA, 2017).

$\mathrm{Na}$ presente análise, é possível afirmar que 30\% dos deputados estaduais eleitos em 2018 possuem parentes que ocupam ou ocuparam cargos políticos eletivos 
de modo a transmitir o seu capital político. Denominamos essa passagem como “capital político herdado”, uma vez que essas relações familiares dotam os indivíduos de um capital que deriva da construção de reputação de outrem.

O número de 30\% é sensivelmente menor que o encontrado por Sardinha (2017), contudo são necessárias duas observações. Em primeiro lugar, optamos por classificar apenas indivíduos que obtiveram um cargo eletivo depois que o outro familiar estava investido de outro. Em outras palavras, Deputados Estaduais eleitos que possuem familiares eleitos com a sua transmissão de “capital político" não são considerados. Importa apenas a transmissão de um familiar para o Deputado Estadual eleito em 2018. Outra observação importante é que se esperava, de antemão, que os números fossem mais baixos, uma vez que o nível de exigência de recursos para a eleição para Deputado Estadual é, em regra, menor que para as eleições para a Câmara ou Senador Federal. Sendo assim, é uma disputa tida como mais aberta a indivíduos com menores posses de capital.

Ainda dentro dos 30\% dos eleitos com “capital político herdado” é possível identificar sensíveis diferenças na comparação entre as Assembleias Legislativas. No gráfico a seguir constata-se que existem Assembleias que haver um familiar político é, de alguma forma, fundamental para o sucesso eleitoral. Já em outros, como é o caso de Santa Catarina ou a Câmara Legislativa do Distrito Federal, os efeitos do capital político são residuais. 


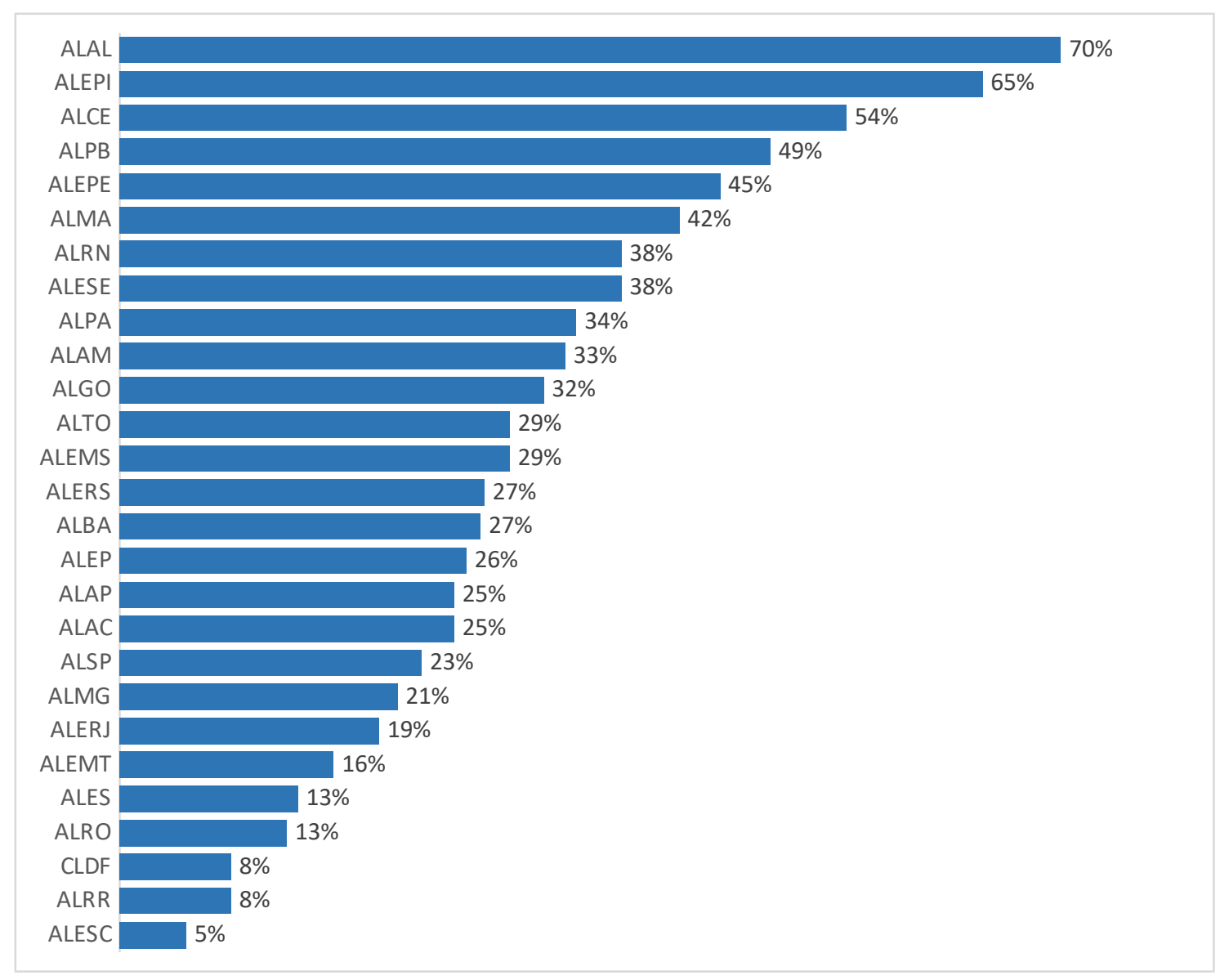

Gráfico 1- Percentual de indivíduos eleitos com "capital político herdado" nas eleições para Assembleias Legislativas em 2018. Dados sistematizados pelo autor

Entre as dez Assembleias que mais estão permeadas por indivíduos dotados do capital herdado, oito estão no Nordeste. Por certo, os dados poderiam ser utilizados para corroborar o argumento de que há espaços de "atraso" na conformação social e política brasileira e os sinais mais claros estariam no Nordeste. Não é intenção do presente artigo confirmar ou refutar essa hipótese. Importa-nos demonstrar que há variação dessa influência em relação aos estados e as regiões do país, conforme gráfico a seguir. 


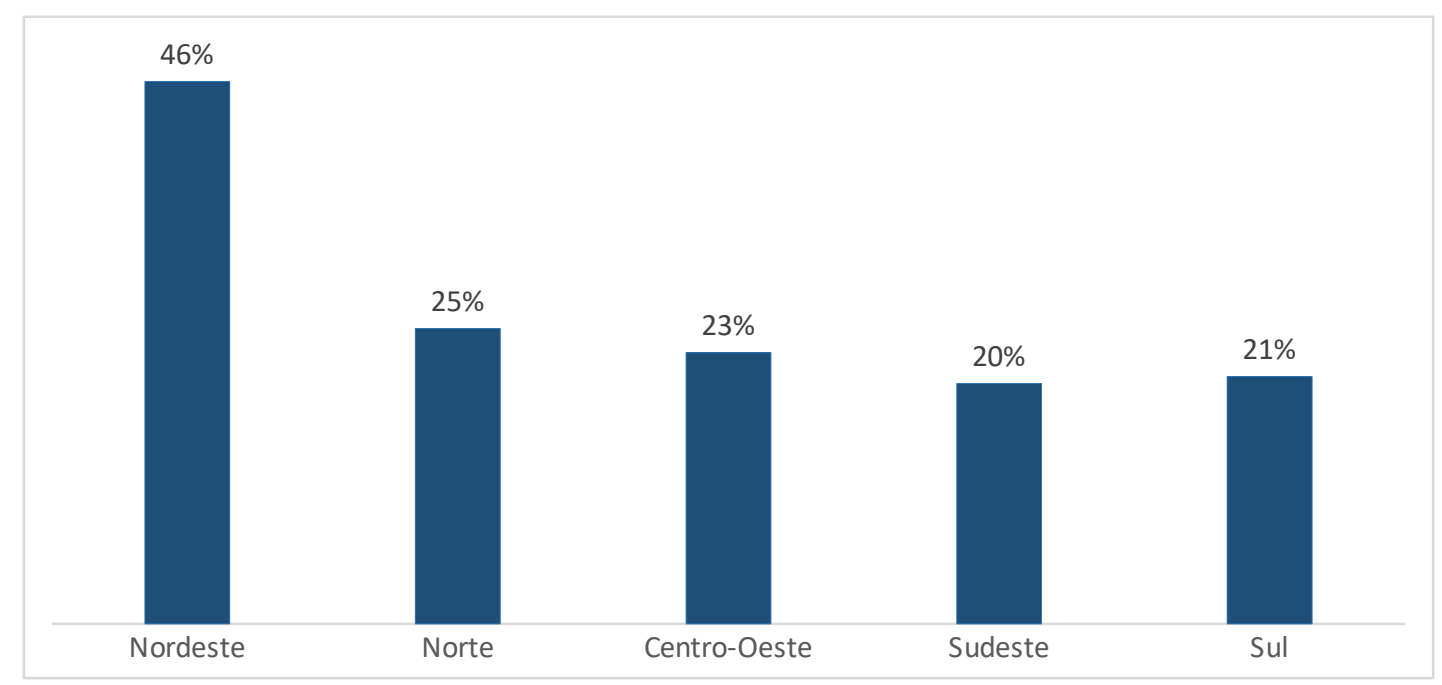

Gráfico 2 - Percentual de "capital político herdado" entre as regiões do país em relação aos eleitos de 2018 para as Assembleias Legislativas. Dados sistematizados pelo autor

Não apenas há variação regional diante dos dados. Um dos objetivos do presente artigo é também verificar de que modo a variável "gênero" é impactada pela influência do capital político herdado em relação aos eleitos. Já há literatura extensa sobre a sub-representação feminina, sempre reforçada pelos constrangimentos sociais e estruturais da sociedade brasileira inscrita na tradição patriarcal e de divisão social do trabalho aqui existente (ARAÚJO, 2010; BIROLI e MIGUEL, 2014; MOTA e BIROLI, 2014). Do total de 1059 Deputados Estaduais empossados em 2019, eleitos em 2018, 16\% são do sexo feminino, percentual semelhante ao conquistado pelas Deputadas Federais. Desse modo, confirma-se a ideia de sub-representação como paradigma histórico-estrutural da representação política brasileira. 


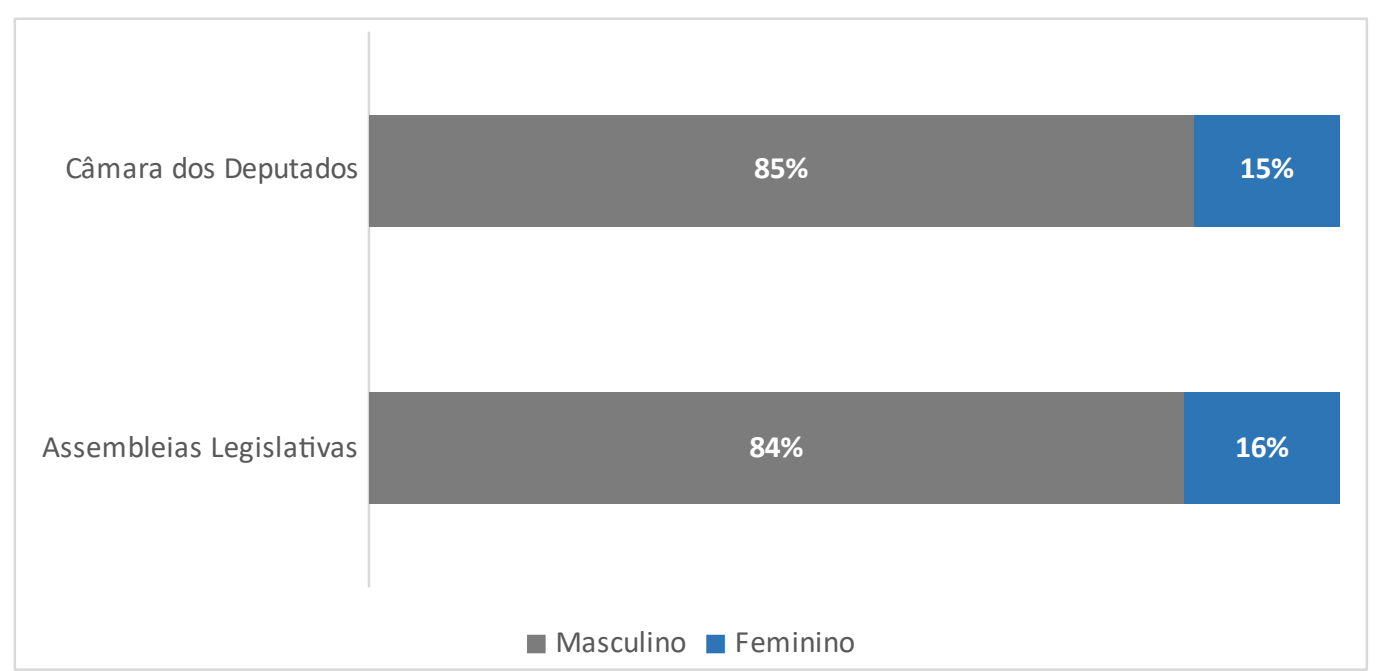

Gráfico 3 - Percentual de eleitos por gênero para a Câmara dos Deputados e para as Assembleias Legislativas no ano de 2018. Dados sistematizados pelo autor.

Para além disso, existem indícios de que mesmo quando eleitas, parte significativa faz parte de um processo mais amplo de um processo de manutenção de poder por parte de um grupo familiar. Em artigo de Lenkic e Guedon (2017) testa-se a hipótese em estudo local na Câmara Municipal do Rio de Janeiro e na Assembleia Legislativa do Rio de Janeiro. O resultado é que o “capital político herdado” é mais sensível para o sucesso eleitoral das mulheres do que o dos homens. Ou seja, ainda que eleitas, credenciam-se como viáveis eleitoralmente a partir da chancela familiar, especialmente masculina (LENKIC e GUEDON, 2017). Um dos objetivos do presente artigo é verificar se os dados podem ser extrapolados para outras regiões do Brasil, em especial nas Assembleias Legislativas.

Conforme demonstrado anteriormente, 30\% dos Deputados eleitos, a despeito do gênero, possuem em sua biografia as marcas de uma herança familiar. Os dados segregados apontam que as mulheres elevam a média, uma vez que quase metade das eleitas possuem essa herança marcada. 


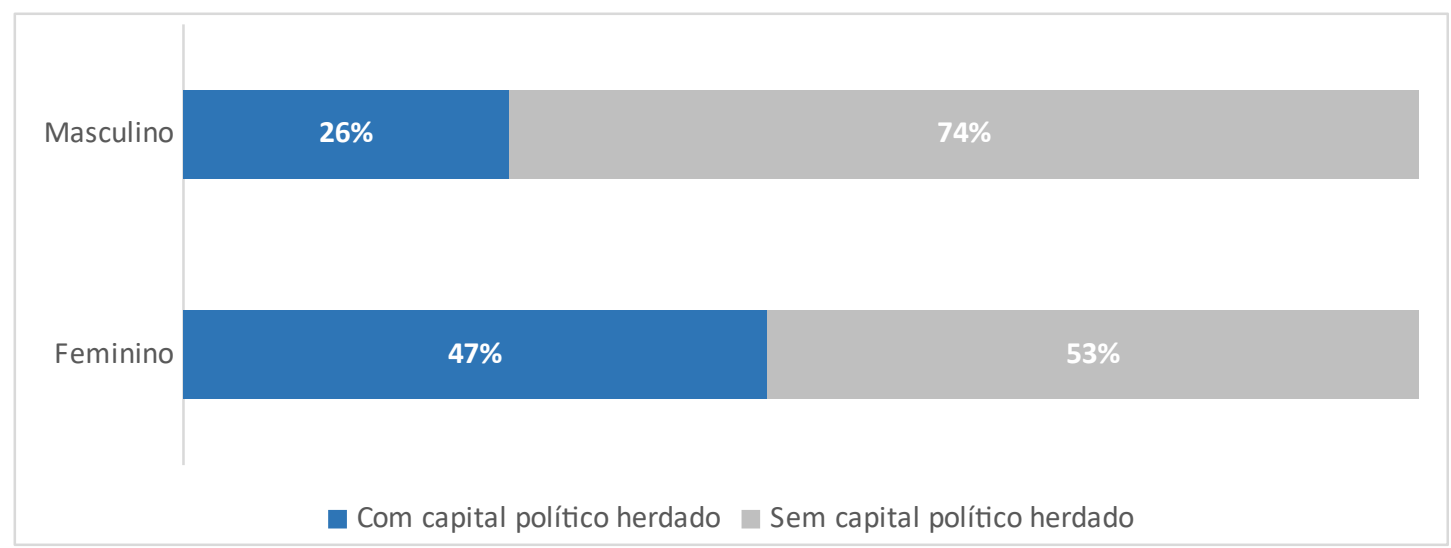

Gráfico 4 - Percentual de indivíduos com "capital político herdado" por gênero para os eleitos para as Assembleias Legislativas em 2018. Dados sistematizados pelo autor.

A diferença chama mais a atenção quanto a origem do capital político. Em relação aos eleitos, é interessante notar que nenhum dos políticos eleitos teve participação da esposa para atingir esse feito. Por outro lado, 58\% das mulheres eleitas e consideradas herdeiras de capital político tiveram a participação do marido. Outra fonte importante desse capital político é a partir da transmissão direta através dos pais. No total, $67 \%$ das transmissões dizem respeito a esse tipo, sendo $78 \%$ no caso dos homens eleitos e $38 \%$ no caso das mulheres.

Conforme já demonstrado, os dados apontam que as mulheres são mais afetadas pela influência de capital político no seu sucesso eleitoral, mas não apenas. A origem desse capital também é masculina, sendo, quase a totalidade dos transmissores (98\%), homens já estabelecidos na vida política institucional.

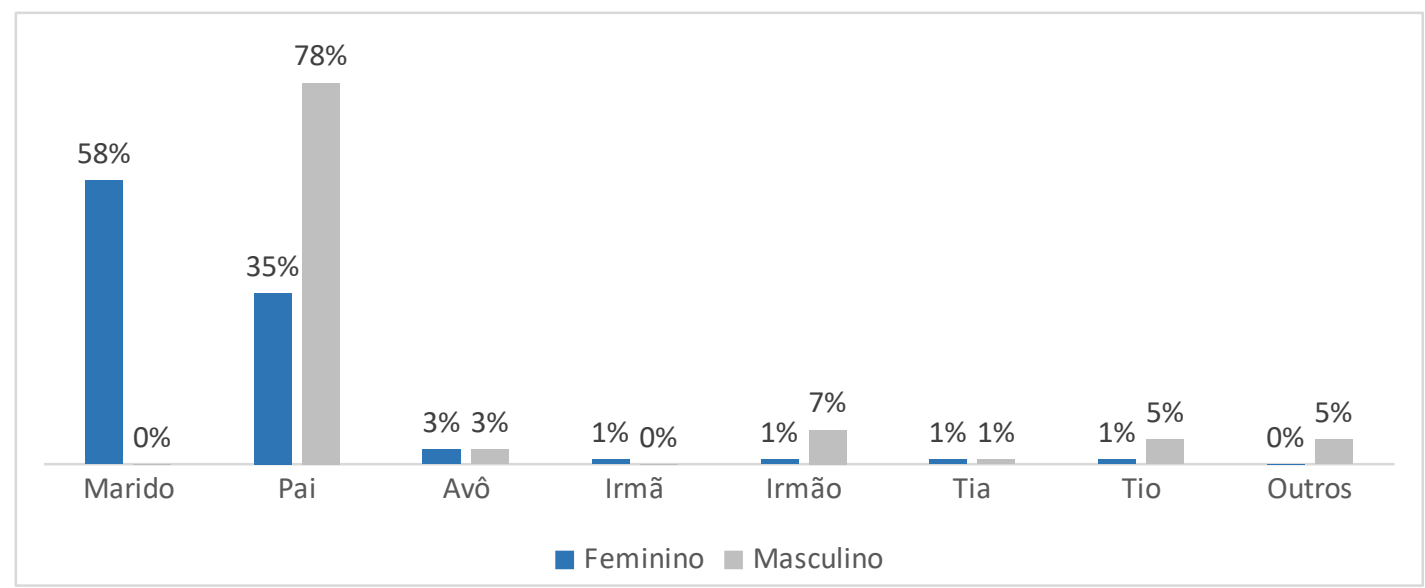

Gráfico 5 - Origem do capital político por gênero para os eleitos das Assembleias Legislativas em 2018. Dados sistematizados pelo autor. 
Em relação ainda aos transmissores, esperava-se que eles ocupassem ou tivessem ocupado posições tidas como mais elevadas na hierarquia de carreira política, considerando a já exposta definição de Miguel (2003). Os dados apontam que mais de 1/3 dos detentores de capital conseguem transmitir seus ganhos eleitorais sendo Prefeitos, e não raramente de pequenos municípios. O controle da máquina municipal torna-se elemento de diferenciação para o sucesso de um apadrinhado político familiar. Além disso, 28\% estiveram com mandato nas Assembleias Legislativas. Costumeiramente são indivíduos que saem da vida pública, por vezes ocupando cargos nos Tribunais de Contas, e indicam seus sucessores. Além desses, 17\% ocupam ou ocuparam cargos de Deputado Federal. Sendo assim, não raros são os casos de "dobradinha”, na qual é utilizada a mesma estrutura da campanha eleitoral com fins de eleger o candidato a Deputado Federal e Deputado Federal.

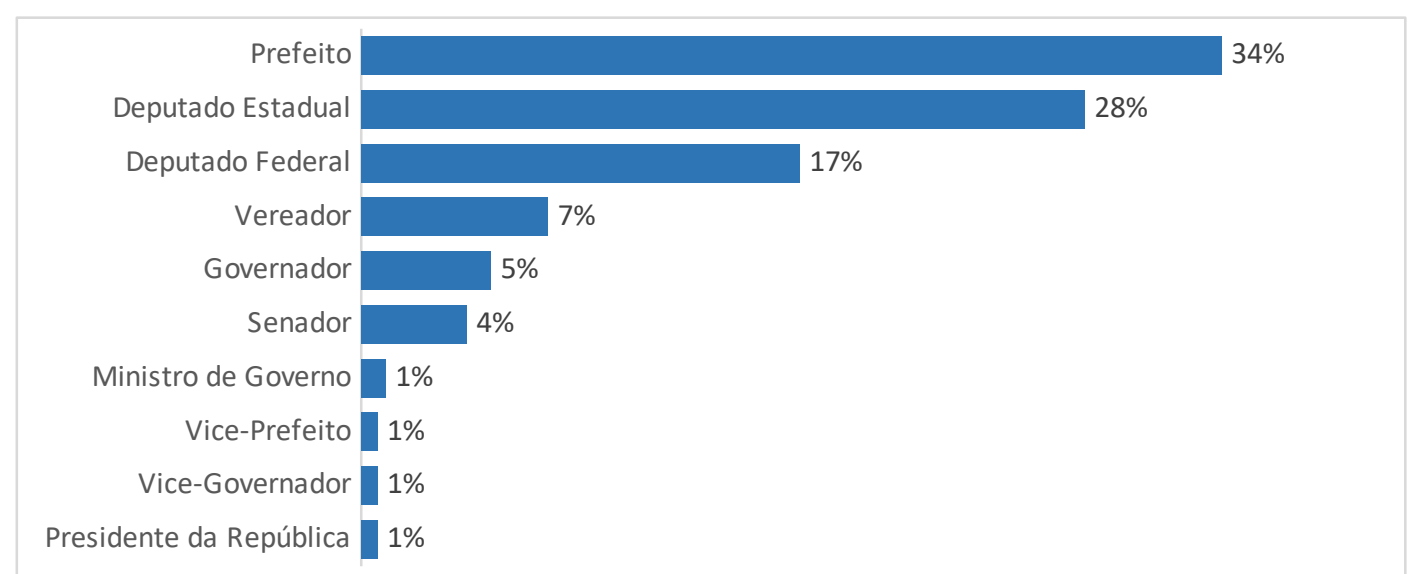

Gráfico 6 - Cargo ocupado pelo indivíduo transmissor de capital político para os eleitos em 2018. Dados sistematizados pelo autor.

Por fim, diante dos dados recolhidos, foi possível também observar diferenças em relação a incidência dessa transferência de capital político entre as legendas partidárias. Essa perspectiva relaciona-se fortemente com a abordagem recentemente adotada por Oliveira (2012), isso porque relaciona as categorias biográficas com a institucionalidade, no caso os partidos políticos.

Na literatura sobre recrutamento partidário e seleção de candidatos já existem indicações de que o filtro ideológico é também um filtro de recrutamento em celeiros diferenciados (RODRIGUES, 2002). Em outras palavras, a depender das ideologias dos 
partidos, o recrutamento responderia a reproduzir lógicas de interesse da legenda em relação aos perfis sociais. Partidos de esquerda, por exemplo, seriam mais aptos a recrutarem indivíduos com menor acúmulo de capitais. Seguindo mesma lógica, esperava-se que o filtro ideológico também agisse sobre a incidência da lógica de transmissão de capitais, sendo os partidos de esquerda menos permeáveis.

Os resultados apontam para a aproximação entre o uso de indivíduos dotados de capital político entre indivíduos de partidos de esquerda ${ }^{7}$ e de direita, tendo os partidos de direita um pequeno maior uso. Por sua vez, os partidos de centro são apresentados como os maiores concentradores dessa lógica. Via de regra, portanto, vêse que é uma estratégia recorrente das legendas, independente da ideologia, especialmente pelo alto êxito eleitoral desses indivíduos.

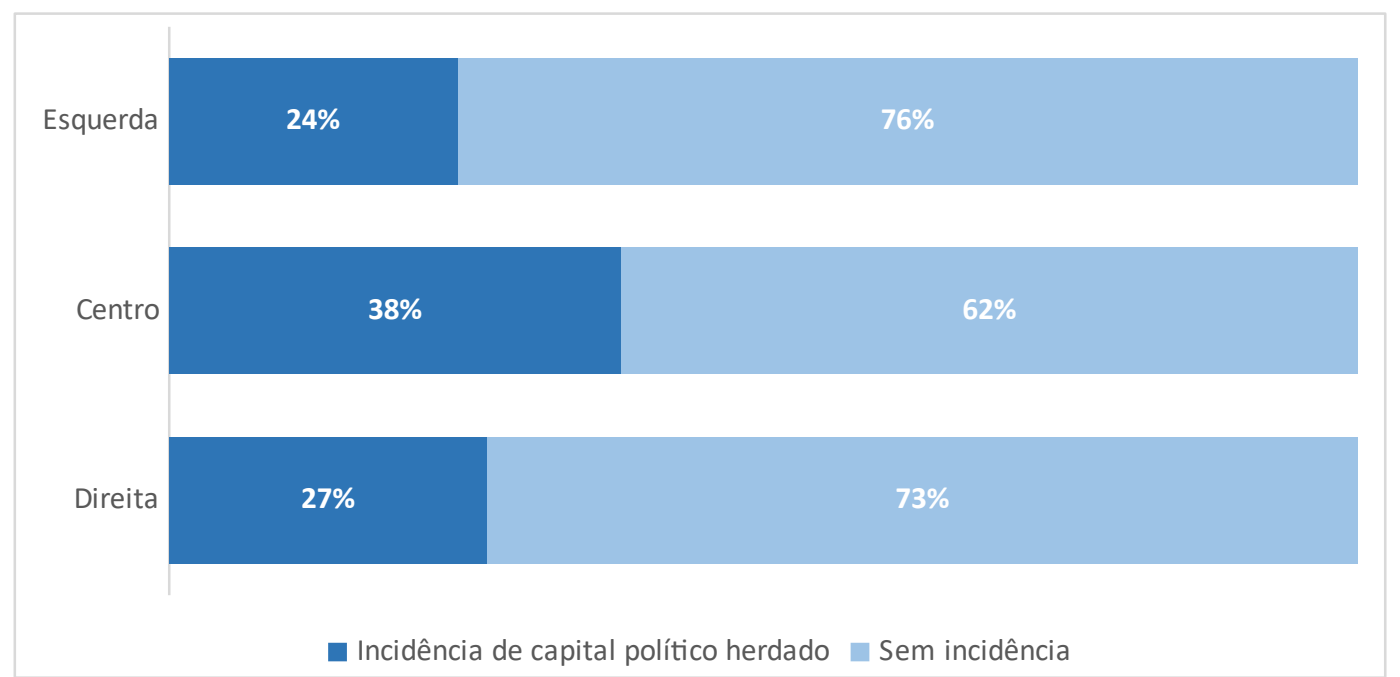

Gráfico 7 - Incidência de capital político herdado por ideologia do partido nos eleitos para as Assembleias Legislativas em 2018. Dados sistematizados pelo autor.

7 Não é intenção do presente artigo debater as formas possíveis de classificação ideológica. São diversas as classificações: a partir de votações no Congresso e pesquisa com parlamentares (Mainwaring, Power e Meneguello (2003), elites dirigentes (Power, 2000), programas partidários (Tarouco e Madeira, 2013), entre outros. Optou-se, no presente artigo, seguir a classificação exposta por Tarouco (2015) a partir de um expert survey aplicado a estudiosos de partidos políticos no Brasil. Isso porque a classificação teria como base a consolidação das variadas formas de classificação, sendo consubstanciada na opinião dos estudiosos. Os partidos não classificados pela métrica foram classificados a partir da observância dos manifestos partidários em relação a características da matriz econômica. Foi o caso do NOVO, Patriotas e PMB na direita; REDE e PPL na esquerda; PROS, PSD, SD no centro. 


\section{Considerações finais}

É inegável que o uso de cargos eletivos quase de forma hereditária é uma marca da política brasileira. Os espaços de representação convivem cotidianamente com os filhos, irmãos e esposas de indivíduos já consolidados no que pode ser chamado de mercado eleitoral. Segundo reportagem do Congresso em Foco, em 2016, herdeiros de políticos ocupariam metade da Câmara dos Deputados ${ }^{8}$.

Significativo também são os dados para as Assembleias Legislativas Estaduais. Conforme os dados apontam, 30\% dos eleitos nas eleições de 2018 para os parlamentos estaduais interagem com a noção de genealogia política, sendo herdeiros de capital político. Esse fenômeno é mais fortemente observado na região Nordeste, mas não deixando de existir de modo considerável nas regiões Sul e Sudeste. Mais de 1/4 dos Deputados Estaduais do Rio Grande do Sul possuem herança política, por exemplo.

Apontamos, inclusive, que os números de 2018 podem ser ainda menores se comparados com outras eleições. Isso porque a eleição de 2018 é tida como um caso paradigmático para a Ciência Política com a eleição de quantidade significativa de candidatos sem experiência prévia, sobretudo a partir da forte votação do Partido Social Liberal. Apenas outras análises empíricas e retrospectivas podem confirmar ou refutar tal impressão.

Além disso, no presente artigo foi possível constatar que as mulheres são mais afetadas pela incidência da transmissão de capital político. Já dentro de um quadro de sub-representação, a superação dessa mazela é apenas realizada de modo parcial, uma vez que o seu êxito passa pela chancela de indivíduos estabelecidos na vida políticorepresentativa. Em outras palavras, via de regra, as mulheres não são eleitas e, quando são, quase metade afetada chancela masculina a partir da transmissão de capital político.

A origem do capital para as mulheres é majoritariamente a partir dos maridos. Já a dos homens, deriva dos pais. Raros foram os casos em que as transmissões partiram de mulheres para homens. A direção é, via de regra, dos homens para as

8 Disponível em: https://congressoemfoco.uol.com.br/especial/noticias/herdeiros-depoliticos-ocupam-metade-da-camara/ (Acessado em 26/11/2019). 
mulheres. Ao fim, os detentores de capital são homens, ocupantes majoritariamente de cargos de Prefeito e Deputados Estaduais, que estruturam novos candidatos ou candidatas de forma a manter o poder dentro dos grupos familiares. E a estratégia mostra-se exitosa.

Além disso, demonstrou-se também que não há uma diferenciação significativa entre as legendas no uso do capital político herdado se considerados os eleitos em 2018. Os partidos de centro privilegiam esse tipo de prática, mas há menor diferenciação entre partidos de esquerda e direita. Isso indica, novamente, que é um uso recorrente e indiscriminado de uma das marcas da política brasileira, que é a manutenção de poder a partir das elites.

Em termos gerais, o artigo advogou por uma perspectiva teórico-metodológica que aproxima os estudos genealógicos com o institucionalismo dos estudos de recrutamento partidário. Isso porque, conforme já demonstrado por Oliveira (2012), as relações familiares não operam no vácuo; entremeiam as relações institucionais e são refletidas e reproduzidas a partir das organizações partidárias. Diante desse novo olhar, abre-se espaço para melhores comunicações entre as perspectivas históricas e politólogas a fim de identificar, de melhor forma, o fenômeno das famílias políticas no Brasil.

\section{Referências}

ARAUJO, Clara. 2010. Rotas de ingresso, trajetórias e acesso das mulheres ao legislativo: um estudo comparado entre Brasil e Argentina. Rev. Estud. Fem., Florianópolis, v.18, n.2, p.567-584.

BIROLI, Flavia; MIGUEL, Luis Felipe. 2014. Feminismo e política: uma introdução. 1 ed - São Paulo: Boitempo.

BORBA, Felipe; CERVI, Emerson Urizzi, 2017. Relação entre propaganda, dinheiro e avaliação de governo no desempenho de candidatos em eleições majoritárias no Brasil. Opinião Pública, Campinas, v. 23, n. 3, p. 754-785.

CARVALHO, José Murilo de. Mandonismo, Coronelismo, Clientelismo: Uma Discussão Conceitual. 1997. Dados, Rio de Janeiro, v. 40, n. 2. 
CERVI, Emerson; COSTA, Luiz Domingos; CODATO, Adriano; PERISSINOTTO, Renato. 2015. Dinheiro, profissão e partido político: a vitória na eleição para deputado federal no Brasil em 2010. Sociedade e Estado, 30(1), pp.189-205.

MASSINO, L. Retratos da Classe Política Brasileira: estudos da ciência política. Novas Edições Acadêmicas. 2015.

DUVERGER, Maurice. Os partidos políticos. São Paulo, Zahar, 1951.

LEITE, Fernando. O campo de produção da Ciência Política brasileira contemporânea: uma análise histórico-estrutural de seus princípios de divisão a partir de periódicos, 15 áreas e abordagens. Curitiba, 2015. Tese apresentada no Programa de Pós-Graduação em Sociologia do Setor de Ciências Humanas, Letras e Artes da Universidade Federal do Paraná, Paraná.

LENKIC, Manuela e GUEDON, Philippe. 2017. A representação feminina no rio de janeiro: a influência do capital político herdado no sucesso eleitoral. CSOnline Revista Eletrônica de Ciências Sociais, Juiz de Fora, n. 23, pp. 193-208.

LYNCH, Christian. Entre a velha e a nova Ciência Política: Continuidade e renovação acadêmica na primeira década da revista DADOS (1966-1976). 2016. DADOS - Revista de Ciências Sociais, Rio de Janeiro, número especial, novembro, pp. 65 a 104.

MAINWARING, Scott; POWER, Timothy e MENEGUELLO, Raquel. Partidos conservadores no Brasil contemporâneo: quais são, o que defendem, quais são suas bases. São Paulo: Paz e Terra, 2003.

MIGUEL, Luis Felipe. 2003. Capital político e carreira eleitoral: algumas variáveis na eleição para o Congresso brasileiro. Revista Sociologia Política, v.20, p.115-134.

MOTA, Fernanda Ferreira e BIROLI, Flávia. 2014. O gênero na política: a construção do "feminino" nas eleições presidenciais de 2010. Cad. Pagu [online], 2014, n.43, pp.197231.

NORRIS, Pippa. Passages to Power. Legislative recruitment in advanced democracies. Cambridge: Cambridge University Press, 1997.

OLIVEIRA, Ricardo Costa de. Na Teia do Nepotismo: sociologia política das relações de parentesco e poder político no Paraná e no Brasil. 1. ed. Curitiba: Editora Insight, 2012.

OLIVEIRA, Ricardo Costa de; GOULART, Mônica Helena Harrich Silva; VANALI, Ana C.; MONTEIRO, José Marciano. 2017. Família, parentesco, instituições e poder no Brasil: retomada e atualização de uma agenda de pesquisa. Revista Brasileira de Sociologia, v.5, n. 11, p. 165-198. 
PERISSINOTTO, Renato; MIRÍADE, Angel. 2009. Caminhos para o Parlamento: Candidatos e Eleitos nas Eleições para Deputado Federal em 2006. Revista DADOS, v. 52, n. 2, p. 301-303.

POWER, Timothy. The Political Right in Postauthoritarian Brazil: Elites, institutions, and democratization. University Park: Pennsylvania State University, 2000.

RODRIGUES, Leôncio M. Partidos, Ideologia e Composição Social: Um Estudo das Bancadas Partidárias da Câmara dos Deputados. São Paulo: Edusp, 2002.

TAROUCO, Gabriela da Silva e MADEIRA, Rafael Machado. 2013. Partidos, programas e o debate sobre esquerda e direita no Brasil. Rev. Sociol. Polit. [online]. vol.21, n.45, pp. 149-165.

TAROUCO, Gabriela e MADEIRA, Rafael Machado. 2015. Os partidos políticos segundo seus estudiosos: análise de um expert survey. Civitas, Porto Alegre, v. 15, n. 1. 